\title{
Enhancement of osteogenesis of rabbit bone marrow derived mesenchymal stem cells by transfection of human BMP-2 and EGFP recombinant adenovirus via Wnt signaling pathway
}

\author{
CHENG-CONG WU ${ }^{1}$, FANG WANG ${ }^{2}$, SHU RONG $^{1}$, JING REN ${ }^{1}$, JIAN-SHAN WAN ${ }^{1}$, \\ LI-XIANG SHI ${ }^{1}$, ZHEN WU ${ }^{1}$, TAO LIU ${ }^{1}$ and QIANG LI ${ }^{3}$ \\ ${ }^{1}$ Department of Orthopedics (I), Qujing No. 1 Hospital; ${ }^{2}$ Department of Pathology, Qujing Second Hospital, Qujing, \\ Yunnan 655000; ${ }^{3}$ Emergency Trauma Surgery, Affiliated Hospital of Guilin Medical University, \\ Guilin, Guangxi 541001, P.R. China
}

Received November 7, 2017; Accepted June 27, 2018

DOI: $10.3892 /$ etm.2018.6735

\begin{abstract}
Bone marrow mesenchymal stem cells (BMSCs) are considered the most important seed cells in bone tissue engineering. The present study aimed to investigate the potential of rabbit BMSCs in osteogenesis after the transfection of human BMP-2 and EGFP recombinant adenovirus. Rabbit BMSCs were isolated and the surface stem cell makers, including CD29, CD44 and CD45 were detected by flow cytometry. The expression of BMP-2 mRNA and protein in BMSCs were detected by reverse transcription-quantitative polymerase chain reaction and western blot analysis, respectively. After an induction with osteogenic medium, the alkaline phosphatase (ALK) activity at 7 days, the type I collagen at 14 days, and the calcium nodules at 21 days were performed using an ALK activity kit, immunohistochemical staining and alizarin red S staining, respectively. The expression levels of proteins related to the Wnt signaling pathway were detected by western blot analysis. The positive rates of $\mathrm{CD} 29, \mathrm{CD} 44$ and $\mathrm{CD} 45$ were $62.92 \pm 1.99,93.55 \pm 0.99$ and $0.21 \pm 0.12 \%$. The expression of BMP- 2 mRNA and protein was significantly upregulated in Ad-BMP-2/EGFP transfected BMSCs. Furthermore, Ad-BMP-2/EGFP induced ALP activity, promoted the production of type I collagen and calcium nodule formation in rabbit BMSCs. The levels of $\beta$-catenin, cyclin D1, Runx2 and c-myc were upregulated in Ad-hBMP-2/EGFP transfected BMSCs, while the level of GSK $3 \beta$ was significantly decreased. Results also indicated that the overexpression of BMP-2 by Ad-hBMP-2/EGFP enhanced the osteogenic differentiation ability of cultured rabbit BMSCs via stimulating the Wnt signaling pathway with the accumulation of $\beta$-catenin and suppression of GSK3 $\beta$. The Ad-hBMP-2/EGFP transfected
\end{abstract}

Correspondence to: Dr Qiang Li, Emergency Trauma Surgery, Affiliated Hospital of Guilin Medical University, 13 Lequn Road Guilin, Guangxi 541001, P.R. China

E-mail: qiangli12251970@aliyun.com

Key words: rabbit, bone marrow derived mesenchymal stem cells, BMP-2, osteogenesis, Wnt pathway rabbit BMSCs are expected to be a good seed cell in bone tissue engineering.

\section{Introduction}

The bone defect caused by various factors is a difficult problem in orthopedics $(1,2)$. At present, the main method to solve this problem is bone grafting, which is the most common tissue graft following blood transfusion (3). In recent years, with the rapid development of tissue engineering and bioengineering, bone tissue engineering has been favored in the clinical application of bone defect repair $(4,5)$.

Bone tissue engineering is mainly composed of three aspects: Seed cells, cytokines and scaffold materials (6). In the study of bone tissue engineering, bone marrow mesenchymal stem cells (BMSCs) are the most studied seed cells, which have capable of self-renewal and of multi differentiation into a variety of bone cells under certain conditions (7-9).

Bone morphogenetic protein (BMP) is an acidic protein found in bone matrix. It belongs to the TGF- $\beta$ superfamily $(10,11)$. It is a multifunctional transforming growth factor group, which consist of at least 20 members. Among them, BMP-2 is one of the most widely studied BMPs in bone tissue engineering, and it is also known to induce osteogenesis (12). BMP-2 is the most commonly used cytokine at present. It can induce pluripotent stem cells BMSCs differentiated into osteoblasts and promote the expression of type I collagen, which can lead to endochondral ossification and promote the formation of new bone (12). Type I collagen is not only an important component of extracellular matrix in bone tissue, but also is one of the markers of osteoblast because it is mainly synthesis and secretion by mature bone cells, and can provide autologous scaffolds for the BMSCs growth, thus playing an important role in maintaining the normal structure and function of bone $(13,14)$. In addition, alkaline phosphatase (ALP) has the potential to improve osteogenic differentiation of BMSCs and is also one of marker enzymes of osteoblast (15).

The efficient osteogenic induction of BMP-2 has been confirmed by many experimental and clinical studies $(11,12)$. BMP-2 can stimulate expression of other growth factor receptors to accelerate bone formation. Kubota et al (16) implanted 
the freeze-dried bone that combined with recombinant human BMP-2 (hBMP-2) into the chest for ectopic osteogenesis, and found that the expression of FGF-4 and FGF receptors increased, and the formation of new bone and mineralization were accelerated. The methods of preparing BMP by purified bone matrix or genetic engineering synthesis are more commonly used, but it was limited by complicated procedures, and low yield $(17,18)$. There are many problems in the method of directly adding growth factor including BMP-2 into the bone grafts in bone tissue engineering in vivo, such as low titer, which remains to further resolved or develop alternative methods. With the rapid development of transgenic technology, the method of adenovirus vector-mediated gene transfection in target cells is considered as an effective way to induce osteogenesis, as the persistent expression of target gene in vivo is the main factor to promote the healing of bone defect (19-22).

In the present study, we isolated and identified the rabbit BMSCs, transfected hBMP-2 and EGFP genes by adenovirus vector into rabbit BMSCs, and detected the osteogenesis by ALP level, type I collagen expression and calcium nodules formation assays. As the important role of Wnt signaling pathway in osteogenesis (23-25), we also explored whether Ad-hBMP-2/EGFP affects the osteogenic ability of rabbit BMSCs via stimulating the Wnt signaling pathway.

\section{Materials and methods}

Reagents. Low glucose DMEM (L-DMEM), trypsin, and fetal bovine serum were purchased from HyClone; GE Healthcare Life Sciences, (Logan, UT, USA). MTT, vitamin C, $\beta$-phosphoglycerol, dexamethasone purchased from Biosharp, Inc., (Seoul, South Korea). Mouse anti-rabbit CD29/CD44/CD45 monoclonal antibody (Abcam, Cambridge, MA, USA), mouse anti-rabbit IgG1 (eBioscience; Thermo Fisher Scientific, Inc., Waltham, MA, USA), and PerCP biotin-conjugated goat anti-mouse IgG (H+L; Jackson ImmunoResearch Laboratories, Inc., West Grove, PA, USA). Horseradish (HRP)-conjugated Goat anti-mouse $\mathrm{IgG}$ and DAB color kit were purchased from ZSGB-Bio, (Beijing, China). Mouse anti-rabbit type I collagen was purchased from Wuhan Bashan Biotechnology Co., Ltd., China. All antibodies were purchased from Bioworld Technology, Inc., (St. Louis Park, MN, USA). TRIzol and HiFi-MMLV Reverse Transcription cDNA Synthesis kit were purchased from Invitrogen; Thermo Fisher Scientific, Inc. SYBR-Green PCR Master Mix was purchased from ABI, USA. Alizarin red was purchased from Sinopharm Chemical Reagent Co., Ltd., (Shanghai, China). The specific PCR primers were designed and synthesized by Invitrogen; Thermo Fisher Scientific, Inc.

Isolation and culture of rabbit BMSCs. New Zealand rabbits were anesthetized with auricular vein intravenous pentobarbital sodium with dose of $40 \mathrm{mg} / \mathrm{kg}$. A $5.0 \mathrm{ml}$ bone marrow was extracted syringe containing $0.2 \mathrm{ml} 600 \mathrm{U} / \mathrm{ml}$ heparin by puncturing with no. 12 myeloid puncture needle at greater trochanter of the femur under aseptic condition. The bone marrow was diluted with L-DMEM (1:1), centrifuged at 1,500 $\mathrm{rpm} / \mathrm{min}$ for $5 \mathrm{~min}$. After removed the supernatant, cells were resuspended in $3 \mathrm{ml}$ L-DMEM and centrifugal separation with an equal volume of Percoll $(1.073 \mathrm{~g} / \mathrm{ml})$ at $2,500 \mathrm{rpm} / \mathrm{min}$ for $20 \mathrm{~min}$. The middle floc mist cell suspension layer was taken, then $5 \mathrm{ml}$ L-DMEM medium was added, mixed, and centrifuged at $1,500 \mathrm{rpm} / \mathrm{min}$ for $5 \mathrm{~min}$. The isolated BMSCs were collected and cultured with complete culture medium containing $15 \%$ fetal bovine serum at $37^{\circ} \mathrm{C}, 5 \% \mathrm{CO}_{2}$, saturated humidity. After $48 \mathrm{~h}$, cell medium was exchanged, and maintained until reached $80 \%$ confluence for passages. BMSCs at passage 3 was used for experiments. The present study was approved by the Animal Care and Use Committee of the Qujing No. 1 Hospital, China.

BMSCs phenotype detection. The third generation of BMSCs $\left(1.5 \times 10^{6}\right)$ was trypsin digestion, centrifuged at $1,500 \mathrm{rpm} / \mathrm{min}$ for $5 \mathrm{~min}$, PBS washed 2 times, and resuspended in $100 \mu \mathrm{l}$ PBS. Cells were incubated with primary mouse anti-rabbit CD29, CD44, or CD45 antibody at room temperature for $30 \mathrm{~min}$, washing with PBS twice, and then resuspended in $100 \mu \mathrm{l}$ PBS. The corresponding second goat anti-mouse PerCP labeled secondary monoclonal antibody was incubated the cells for $30 \mathrm{~min}$ in the dark. After PBS washing three times, cells were resuspended in $300 \mu \mathrm{l} \mathrm{PBS}$ and analysis of positive rates of CD29, CD44 and CD45 were performed by FACSAriaTM III flow cytometry (BD, USA).

Transfection of BMP-2 and EGFP gene into BMSCs by adenovirus vector. The third generation of BMSCs were growth at Petri dish. At 70-80\% confluence, the culture medium was replaced to serum-free L-DMEM. and BMSCs were infected with Ad-BMP-2/EGFP with multiplicity of infection (MOI) 50, 100 , or 200 . After $24 \mathrm{~h}, \mathrm{BMSCs}$ were cultured with complete culture medium containing $15 \%$ fetal bovine serum. After $48 \mathrm{~h}$, the expression of green fluorescent protein in BMSCs was observed under inverted fluorescence microscope (Olympus Corporation, Tokyo, Japan) to detect the infection efficiency and determine the optimum MOI. Empty adenovirus (negative control (NC)) and Ad-EGFP were set as control.

The expression of $h B M P-2$ gene was detected by reverse transcription-quantitative polymerase chain reaction ( $R T-q P C R)$. According to the hBMP2 gene sequence in the NCBI database, the specific PCR primers were designed and synthesized. GAPDH as the internal reference. The primer sequence used as follow: GAPDH, Forward primer: 5-CCAGAACATCCCTGC CTC-3, Reverse primer: 5-TAGCCAAATTCGTTGTCATAC CA-3; hBMP2, Forward primer: 5-ACTACCAGAAACGAG TGGGAA-3, Reverse primer: 5-GCATCTGTTCGGAAAACC T-3. RNA from BMSCs in Ad-BMP-2/EGFP, Ad-EGFP and NC groups (empty adenovirus) ( $72 \mathrm{~h}$ post transfection) were extracted by TRIzol, and the concentrations and purity were detected by UV spectrophotometer. RNA samples with A260/A280 ratios in range of 1.8 to 2.1 were used for subsequent experiments. CDNA synthesis was performed according to the instructions of the reverse transcription kit. The synthetic CDNA is stored at $-20^{\circ} \mathrm{C}$. qPCR was performed using ABI 7500 Real-time PCR instrument (USA) with SYBR-Green PCR Master Mix kit. The PCR reaction conditions: $50^{\circ} \mathrm{C} 2 \mathrm{~min}, 95^{\circ} \mathrm{C} 10 \mathrm{~min}, 95^{\circ} \mathrm{C} 15 \mathrm{sec}$ 40 cycles; $60^{\circ} \mathrm{C} 1 \mathrm{~min}$. hBMP2 expression was analyzed using $2^{-\Delta \Delta \mathrm{Ct}}$ methods (26).

The expression of hBMP-2 and Wnt-related pathway proteins were detected by western blot. Protein was extracted from 

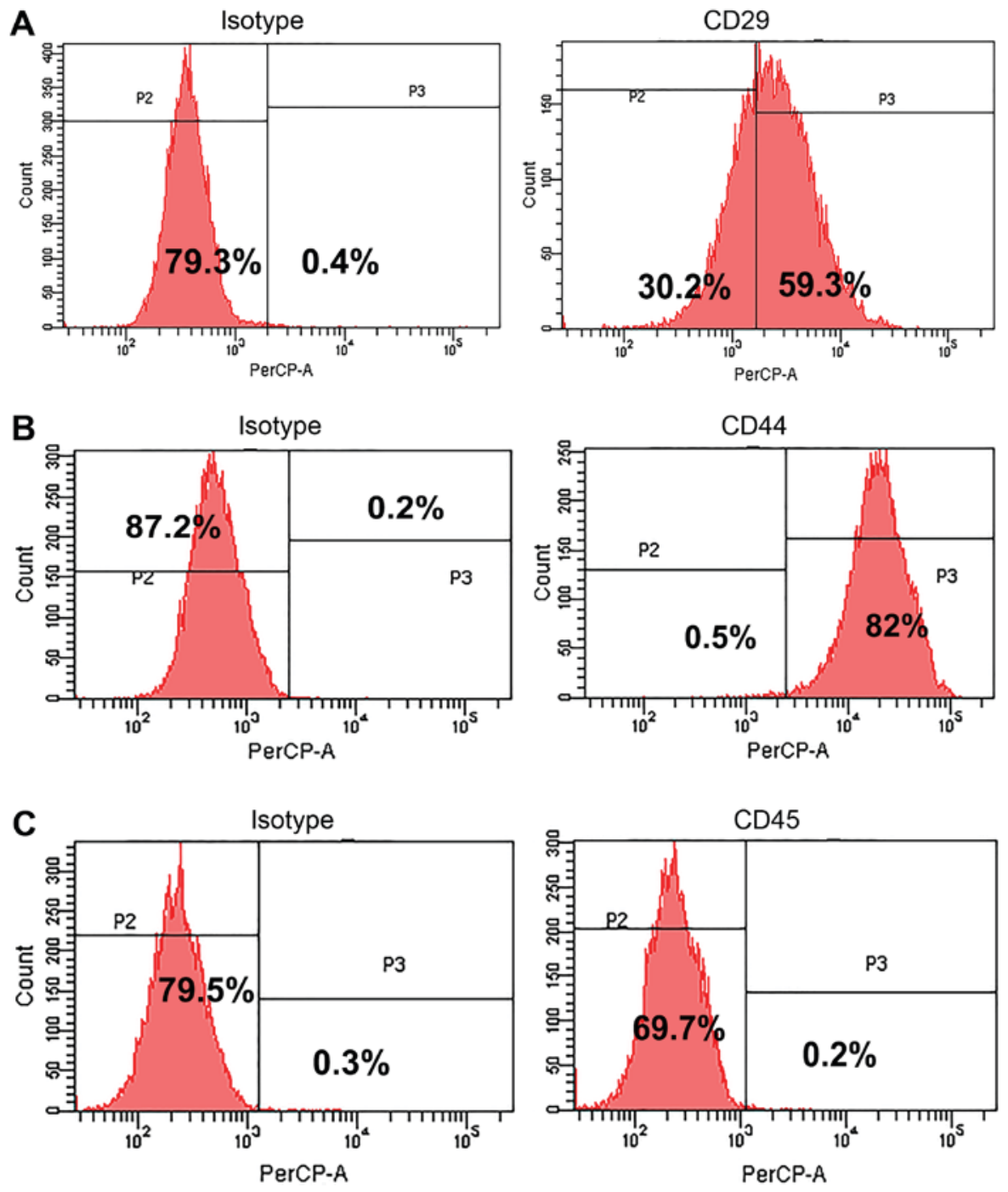

Figure 1. Detection of stem cell surface markers on isolated BMSCs by flow cytometry. (A) CD29; (B) CD44; (C) CD45. A represent image was shown. The positive rates of $\mathrm{CD} 29, \mathrm{CD} 44$, and $\mathrm{CD} 45$ were $62.92 \pm 1.99,93.55 \pm 0.99$, and $0.21 \pm 0.12 \%$, respectively.

BMSCs in Ad-BMP-2/EGFP, Ad-EGFP and NC groups (48 h post transfection) with RIPA. The concentration was quantified by BCA protein concentration assay. $30 \mu \mathrm{g}$ proteins were boiling $10 \mathrm{~min}$, centrifugal $10 \mathrm{sec}$, and separated by $10 \%$ SDS-polyacrylamide gel electrophoresis at $80 \mathrm{~V}, 60 \mathrm{~min}$, and $120 \mathrm{~V}, 30 \mathrm{~min}$, and electrophoresis into PVDF at 90A for $50 \mathrm{~min}$. The blots were blocked in 5\% non-fat milk overnight at $4^{\circ} \mathrm{C}$, incubated with primary BMP- 2 monoclonal antibody, Anti- $\beta$-catenin, anti-p- $\beta$-catenin, anti-GSK $3 \beta$, anti-p-GSK3 $\beta$, anti-Runx2, anti-cyclin D1 or anti-c-myc for $1 \mathrm{~h}$, and HRP-conjugated secondary antibody for $1 \mathrm{~h}$ at room temperature. ECL was used to incubate the blots for $1 \mathrm{~min}$, and blots were imaged by gel imager (JS-780; Shanghai Peiqing Science $\&$ Technology, Co., Ltd., Shanghai, China).

Detection of ALP, type I collagen, and calcium nodules for osteogenic differentiation. After transfection, osteogenic medium (L-DMEM containing $10^{-8} \mathrm{~mol} / \mathrm{l}$ dexamethasone, $50 \mathrm{mg} / \mathrm{l}$ vitamin C, $10 \mathrm{mmol} / \mathrm{l}$ beta glycerophosphate, $15 \%$ fetal bovine serum) was used to induce osteogenic differentiation of BMSCs. After induction of 7 days, the ALP activity was examined by ELISA kit according to the kit instructions, and OD value was measured by MLDEL680 ELISA detector (Bio-Rad Laboratories, Inc., Hercules, CA, USA) at $520 \mathrm{~nm}$. After induction of 14 days, the cells were fixed with $4 \%$ paraformaldehyde, permeabilized with $1 \%$ Triton-X100, and blocked with $1 \%$ BSA. Then, cells were incubated with primary mouse anti-rabbit type I collagen antibody overnight at $4^{\circ} \mathrm{C}$, HPR-conjugated secondary goat anti-mouse antibody at room temperature for $1 \mathrm{~h}$. DAB colored, stained, dehydrated, transparent, lining, and then the expression of type I collagen was observed under light microscope. After induction of 21 days, alizarin red S staining was performed. BMSCs were immobilization, rinse, and incubated with $0.1 \%$ (mass/volume) alizarin red solution for $5 \mathrm{~min}$ at room temperature, rinsed 3 times, and the calcium nodules was observed under microscope.

Statistical analysis. All data were presented as mean \pm standard deviation (SD) at least three experimental repeats. The statistical analysis was performed using SPSS v.16.0 (IBM Corp., Armonk, NY, USA). Multigroup comparisons of the means were carried out by one-way analysis of variance (ANOVA) test with post hoc contrasts by Student-Newman-Keuls test. $\mathrm{P}<0.05$ was considered to indicate a statistically significant difference. 


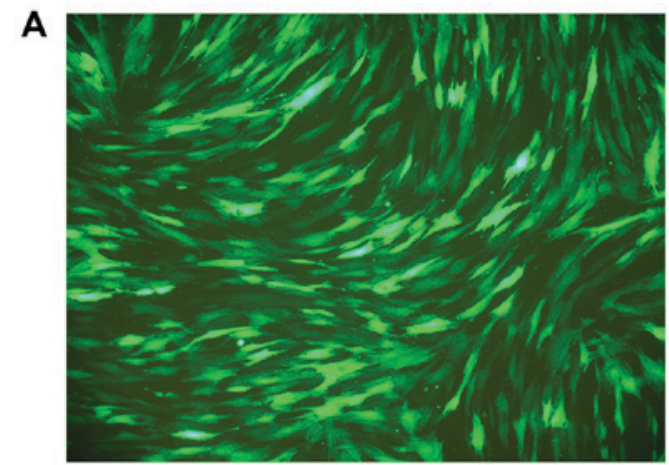

Ad-BMP-2/EGFP BMSCs (MOI=100)
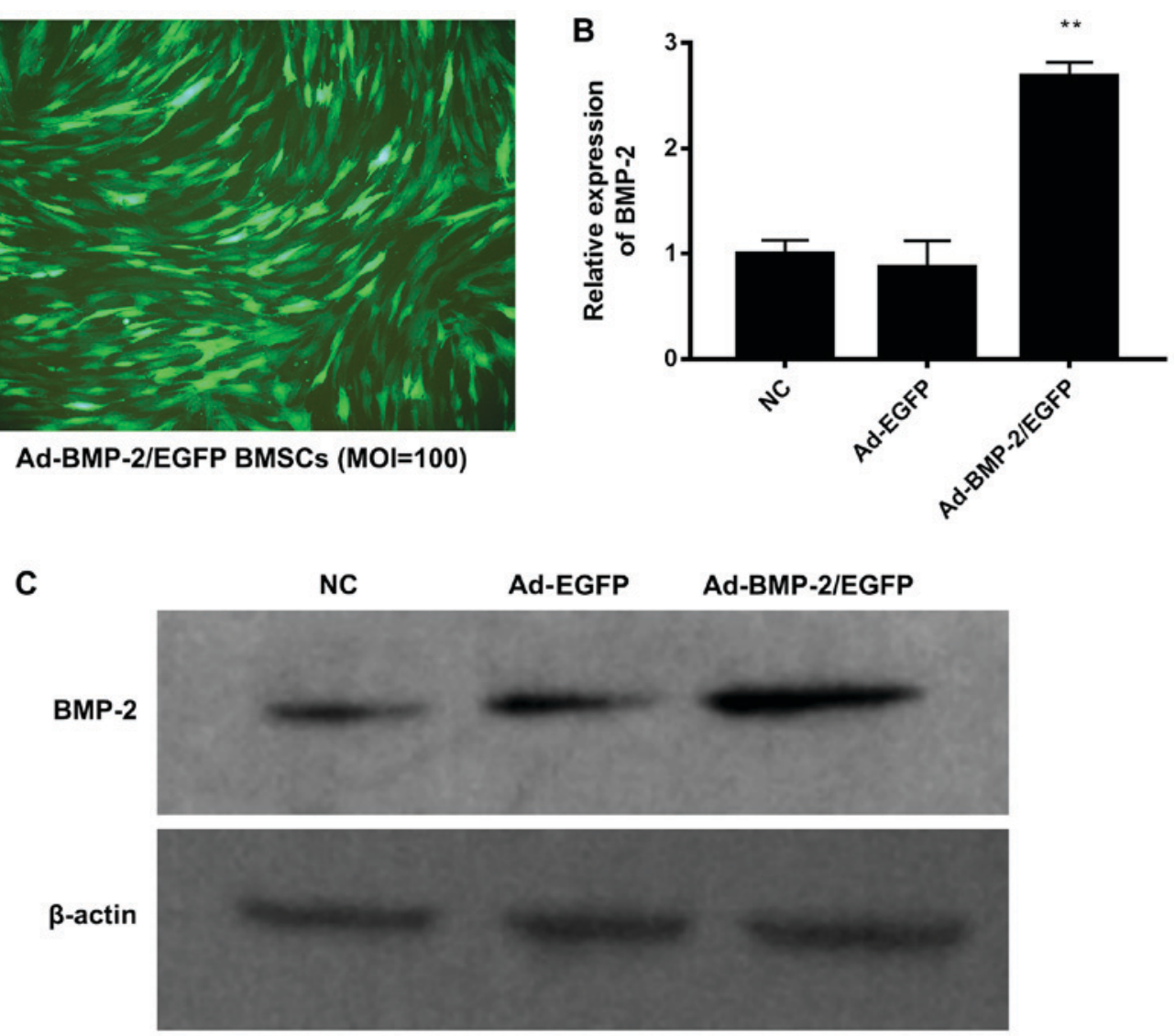

Figure 2. Transfection of Ad-BMP-2/EGFP in rabbit BMSCs. (A) Transfection efficient was detected after transfection for $48 \mathrm{~h}$ (MOI 100) by fluorescence microscope (magnification, x100). The rabbit BMSCs were transfected with empty adenovirus (NC), Ad-EGFP or Ad-BMP-2/EGFP. (B) Expression of BMP-2 mRNA was performed by reverse transcription-quantitative polymerase chain reaction. (C) Expression of BMP-2 protein was performed using western blot analysis. ${ }^{* *} \mathrm{P}<0.01 \mathrm{vs}$. NC.

\section{Results}

Identification of the isolated rabbit BMSCs. The surface markers were detected to identify the rabbit BMSCs. The isolated cell at passage 20 were labeled with anti-CD29, anti-CD44, and anti-CD45 and examined by flow cytometry (Fig. 1). The results showed that CD44 and CD29 were positive expression with a positive rate of $93.55 \pm 0.99 \%$ (Fig. 1B) and $62.92 \pm 1.99 \%$ (Fig. 1A), respectively, but CD45 was negative expression and its positive rate was only $0.21 \pm 0.12 \%$ (Fig. 1C). The results suggested the isolated rabbit cells were BMSCs.

Transfection of rabbit BMSCs with Ad-BMP-2/EGFP. The rabbit $\mathrm{BMSCs}$ were transfected with empty adenovirus, Ad-EGFP or Ad-BMP-2/EGFP. After transfection of $48 \mathrm{~h}$, it was observed that the transfection efficiency was more than 95\% with good cell growth state (MOI:100) by fluorescent microscopy (Fig. 2A). When MOI was 50, the transfection efficient was about $60 \%$. When MOI was 200 , the transfection efficient was not significantly increased compared to MOI 200, but there were floating cells and cell morphology was changed from long spindle into fan-shaped distribution, which may be due to adenovirus cytotoxicity (data not shown). Thus, the optimal MOI was 100, which was used in the followed experiments.

The rabbit BMSCs were transfected with empty adenovirus (NC), Ad-EGFP or Ad-BMP-2/EGFP. After transfection of

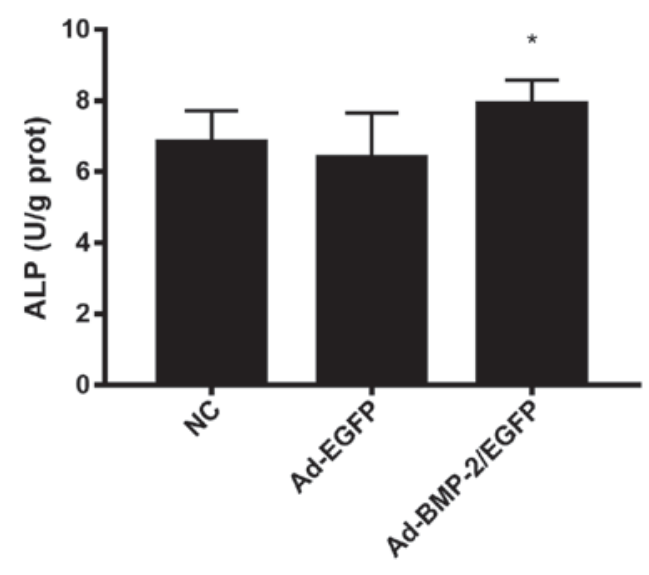

Figure 3. ALP level in Ad-BMP-2/EGFP transfected rabbit BMSCs. After induction with osteogenic medium (L-DMEM containing $10^{-8} \mathrm{~mol} / \mathrm{l}$ dexamethasone, $50 \mathrm{mg} / \mathrm{l}$ vitamin C, $10 \mathrm{mmol} / \mathrm{l}$ beta glycerophosphate, $15 \%$ fetal bovine serum) for 7 days, ALP measurement was performed. "P $<0.05$ vs. NC. ALP, alkaline phosphatase; BMSCs, bone marrow mesenchymal stem cells.

$48 \mathrm{~h}$, the expression of BMP-2 mRNA and protein was detected by RT-qPCR and western blot (Fig. 2B and C). The BMP-2 mRNA was significantly upregulated in Ad-BMP-2/EGFP transfected BMSCs, compared with NC and Ad-EGFP transfected BMSCs (Fig. 2B). Consistently, the BMP-2 protein was significantly upregulated by Ad-BMP-2/EGFP (Fig. 2C). Thus, the BMP-2 was upregulated in rabbit BMSCs. 

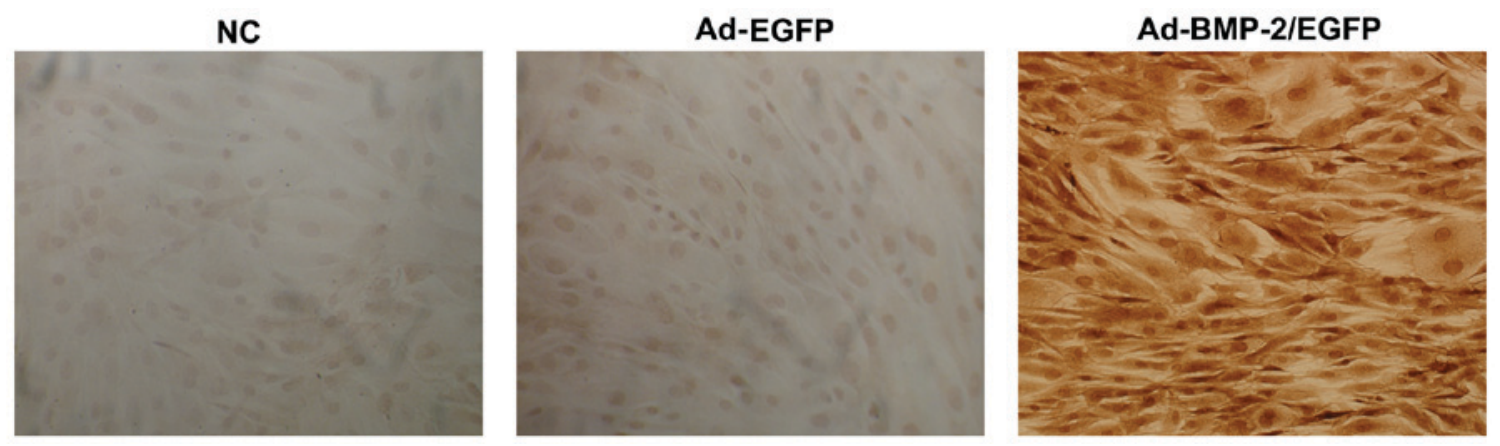

Figure 4. Type I collagen level in Ad-BMP-2/EGFP transfected rabbit BMSCs. After induction with osteogenic medium (L-DMEM containing $10^{-8}$ mol/1 dexamethasone, $50 \mathrm{mg} / \mathrm{l}$ vitamin C, $10 \mathrm{mmol} / \mathrm{l}$ beta glycerophosphate, $15 \%$ fetal bovine serum) for 14 days, immunohistochemical detection of type I collagen was performed. BMSCs, bone marrow mesenchymal stem cells.

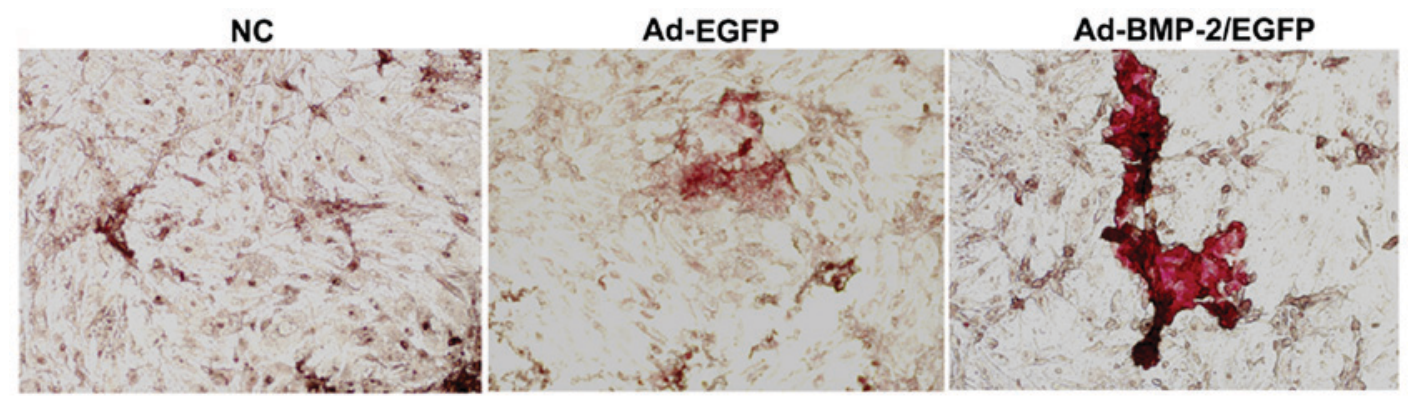

Figure 5. Formation of mineralized nodules in Ad-BMP-2/EGFP transfected rabbit BMSCs. After induction with osteogenic medium (L-DMEM containing $10^{-8} \mathrm{~mol} / \mathrm{l}$ dexamethasone, $50 \mathrm{mg} / \mathrm{l}$ vitamin $\mathrm{C}, 10 \mathrm{mmol} / \mathrm{l}$ beta glycerophosphate, $15 \%$ fetal bovine serum) for 21 days, alizarin red $\mathrm{S}$ staining was performed (magnification, x100). BMSCs, bone marrow mesenchymal stem cells.
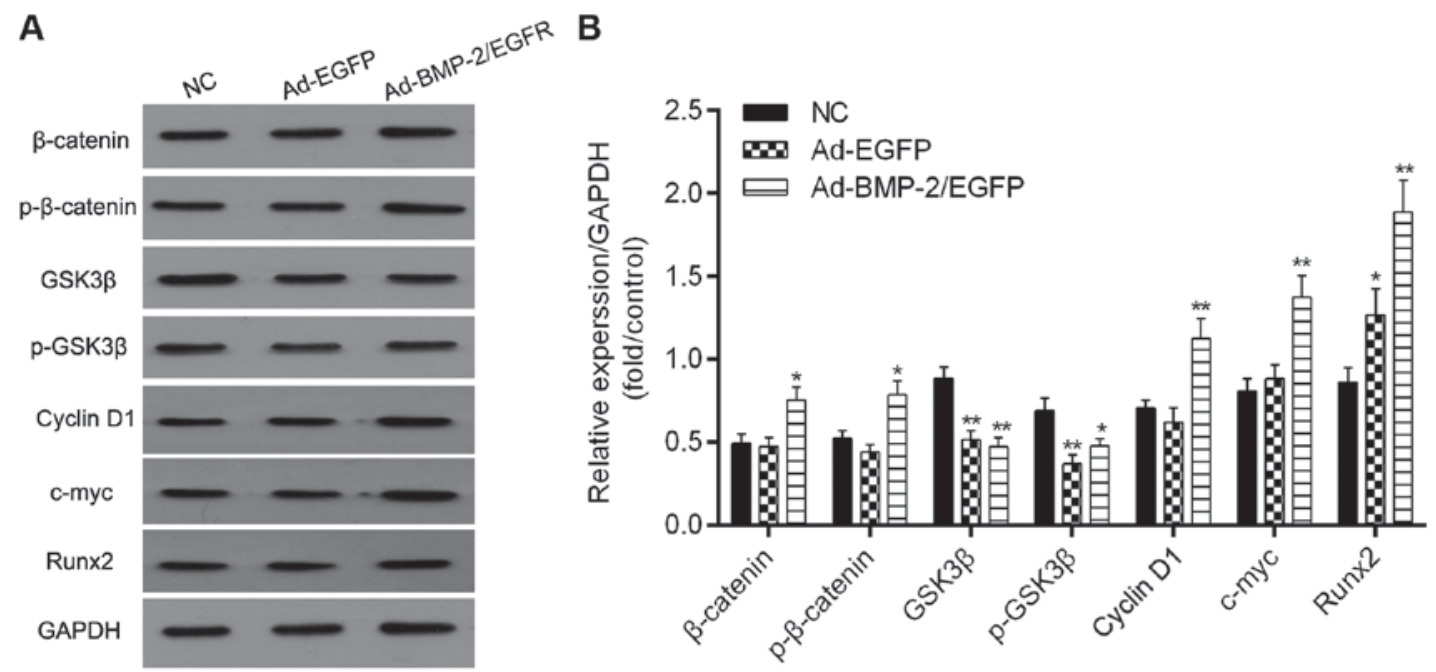

Figure 6. Detection of Wnt signaling marks. After induction with osteogenic medium (L-DMEM containing $10^{-8} \mathrm{~mol} / \mathrm{l}$ dexamethasone, $50 \mathrm{mg} / 1 \mathrm{vitamin} \mathrm{C}$, $10 \mathrm{mmol} / \mathrm{l}$ beta glycerophosphate, $15 \%$ fetal bovine serum) for 21 days. (A) The expression of $\beta$-catenin, p- $\beta$-catenin, GSK3 $\beta$, p-GSK3 $\beta$, cyclin D1, c-myc and Runx2 were detected using western blot analysis. (B) Protein levels of $\beta$-catenin, p- $\beta$-catenin, GSK3 $\beta$, p-GSK3 $\beta$, cyclin D1, c-myc and Runx2 quantified by densitometry. ${ }^{*} \mathrm{P}<0.05$ and ${ }^{* *} \mathrm{P}<0.01$ vs. NC.

Ad-BMP-2/EGFP promotes osteogenesis of rabbit BMSCs. To detect the osteogenesis of rabbit BMSCs after transfection, ALP measurement was performed in cells after induction with osteogenic medium (L-DMEM containing $10^{-8} \mathrm{~mol} / \mathrm{l}$ dexamethasone, $50 \mathrm{mg} / \mathrm{l}$ vitamin C, $10 \mathrm{mmol} / \mathrm{l}$ beta glycerophosphate, $15 \%$ fetal bovine serum) for 7 days (Fig. 3). Ad-BMP-2/EGFP induced ALP compared with NC and Ad-EGFP groups.
Immunohistochemical detection of type I collagen in BMSCs were performed after 14 days of induction (Fig. 4). In Ad-BMP-2/EGFP transfected cells, brown yellow staining was shown, suggesting positive expression of type I collagen. The rabbit BMSCs transfected with NC and Ad-EGFP showed a negative expression of type I collagen. Thus, upregulation of BMP-2 in rabbit BMSCs promoted production of type I collagen. 
After induction with osteogenic medium for 21 days, the alizarin red S staining was performed (Fig. 5). In Ad-BMP-2/EGFP transfected cells, obvious mineralized nodules were formed with red staining, in contrast, no calcium nodules were formed in NC and Ad-EGFP group. Thus, overexpression of BMP-2 enhanced osteogenic differentiation ability of cultured rabbit BMSCs.

Expression of Wnt signaling-related proteins. The expression levels of Wnt signaling-related proteins including $\beta$-catenin, p- $\beta$-catenin, GSK3 $\beta$, p-GSK3 $\beta$, cyclin D1, c-myc and Runx 2 were examined by western blot (Fig. 6). A significant increase in the protein expression levels of $\beta$-catenin, cyclin D1, Runx 2 and c-myc were found in Ad-hBMP-2/EGFP transfected BMSCs, and the levels of GSK $3 \beta$ and p-GSK $3 \beta$ were significantly decreased. Thus, these results suggested that activation of Wnt signaling was responsible for the Ad-hBMP-2/EGFP-induced bone formation.

\section{Discussion}

In the present study, we isolated and identified the rabbit BMSCs, which was highly expressed CD44 and lowly expressed CD45. The positive rate of CD29 is only $62.92 \pm 1.99 \%$, suggesting these cells are not CD29-dependent. Those cells showed a strong osteogenic differentiation ability after Ad-BMP-2/EGFP transfection. The rabbit BMSCs provides enough BMP-2 protein for osteogenic differentiation, which is expected to become the ideal seed cells in bone tissue engineering.

In recent years, the researches of stem cells have provided new ideas for bone tissue engineering $(27,28)$. It has been confirmed that BMSCs has significant differentiation ability of osteoblasts in vitro in the treatment of specific chemical substances including $\beta$-phosphoglycerol, dexamethasone and vitamin $C$; cytokines and mechanical mechanics stimulation $(28,29)$. Many factors including cytokines can induce BMSCs to differentiate into osteoblasts. The most important one of the cytokines are BMPs $(28,30)$. BMP is a major regulatory factor for the differentiation of BMSCs into osteoblasts among a number of factors that activate or inhibit the osteoblastic signaling pathways. The increase in BMP contents promotes the differentiation of BMSCs into osteoblasts. Ishikawa et al (31), used hBMP2 to incubate the in vitro cultures of BMSCs, and found hBMP-2 enhanced cell proliferation, while maintain osteogenic differentiation in the process of passage.

The mainstream approach used in bone tissue engineering is to release BMP directly from biomaterials to the site where bone or cartilage tissue needs to be regenerated. If large bone remodeling is required for prolonged induction of BMSCs, the researchers trend to choose a controlled release carrier or scaffold. Simmons et al (32) used sodium alginate hydrogel as bio-scaffold to combine with BMP-2 and/or transforming growth factor beta 3 (TGF- $\beta 3$ ), to induce the osteogenic differentiation of BMSCs in SCID mice. They found that the effective protein concentration of BMP-2 in the osteogenesis is associated with the biological scaffold materials. The nature BMP induced BMSCs ossification in a dose-dependent manner. Roostaeian et al (33) used hBMP-2 to induce the osteogenesis of rabbit BMSCs, and found that the best suitable concentration of BMP-2 is $50 \mathrm{ng} / \mathrm{ml}$. Wang et al (34) found that, in mouse BMSCs after treatment of BMP-2, ALP level and mineralization was only induced in a very low extent, but the osteogenic differentiation ability of BMSCs was significantly increased when combined use of bone foaming medium with BMP-2. In our study, the BMP-2 and EGFP genes can be efficiently introduced into rabbit BMSCs by recombinant adenovirus vector, which increased ALK, type I collagen, and calcium nodules, thus accelerated the osteogenesis.

Zhu et al (35) infected the goat BMSCs with recombinant adenovirus containing BMP-7 gene and used in the treatment of segmental bone defect. They found BMP-7 can significantly promote new bone formation, and the biomechanics of new bone meet the physiological requirements after operation for 5 months (35). Xu et al (36) used adenovirus mediated BMP2 gene transfection goat BMSCs to treat the bone defect, and found the maximum compressive strength was increased after 24 weeks, but with a persistent humoral immune response. The role of rabbit BMSCs with recombinant adenovirus containing BMP-2 gene will studied in the future.

Li et al (37), demonstrated that BMP2 activated the Wnt signaling pathway by upregulating $\beta$-catenin and cyclin D1, but downregulating GSK3 $\beta$. Previously, Qian et al (38) reported that in the BMP2-induced diabetic BMSCs, the levels of GSK $3 \beta$ and p-GSK3 $\beta$ were significantly reduced, and the levels of Runx2, OSX, cyclin D1 and c-myc were significantly increased. In our study, Ad-hBMP-2/EGFP induced significant increases in the protein expression levels of $\beta$-catenin, cyclin D1, Runx 2 and c-myc in rabbit BMSCs, and decreases in the levels of GSK3 $\beta$ and p-GSK3 $\beta$, which is in agreement with previous studies.

In conclusion, the transfected BMSCs can provide the source of BMP-2 protein and also provide BMP-2 self-target cells, which might promote osteogenesis of rabbit BMSCs via activation of Wnt signaling pathway. Our results provided the novel evidence to support rabbit BMSCs as the best seed cell in bone tissue engineering, and a foundation for the treatment of bone defect in animal model by Ad-hBMP-2/EGFP as it induces the differentiation of rabbit BMSCs into osteoblasts. However, further studies are needed to validate this observation that Ad-hBMP-2/EGFP induced osteogenesis of BMSCs in vivo. Moreover, it will be necessary to further explore the functions and mechanisms of Ad-hBMP-2/EGFP in osteogenesis of BMSCs.

\section{Acknowledgements}

Not applicable.

\section{Funding}

The present study was supported by the National Natural Science Foundation of China (grant no. 31160199) and the Research Foundation of the Department of Education of Yunnan Province (grant no. 2016ZDX074).

\section{Authors' contributions}

CCW, FW, SR, JR, JSW, LXS, ZW, TL and QL made substantial contributions to the conception and design of the present the study. CCW, FW, SR and JR performed the experiments. $\mathrm{CCW}$ wrote the paper. $\mathrm{CCW}$ and $\mathrm{QL}$ revised the manuscript 
critically for important intellectual content. All authors read and approved the manuscript.

\section{Ethics approval and consent to participate}

The present study was approved by the Animal Care and Use Committee of Qujing No. 1 Hospital and experiments were performed in accordance with the policies and principles in the Guide for Care and Use of Laboratory Animals.

\section{Patient consent for publication}

Not applicable.

\section{Competing interests}

The authors declare that they have no competing interests.

\section{References}

1. Lutolf MP and Hubbell JA: Synthetic biomaterials as instructive extracellular microenvironments for morphogenesis in tissue engineering. Nat Biotechnol 23: 47-55, 2005.

2. Nakashima $\mathrm{M}$ and Reddi AH: The application of bone morphogenetic proteins to dental tissue engineering. Nat Biotechnol 21: 1025-1032, 2003

3. Hosseinkhani H, Hong PD and Yu DS: Self-assembled proteins and peptides for regenerative medicine. Chem Rev 113: 4837-4861, 2013.

4. Main RP: Osteocytes and the bone lacunar-canalicular system: Insights into bone biology and skeletal function using bone tissue microstructure. Int J Paleopathol 18: 44-46, 2017.

5. Rao SH, Harini B, Shadamarshan RPK, Balagangadharan K and Selvamurugan N: Natural and synthetic polymers/bioceramics/bioactive compounds-mediated cell signalling in bone tissue engineering. Int J Biol Macromol 110: 88-96, 2018.

6. Daly AC, Freeman FE, Gonzalez-Fernandez T, Critchley SE, Nulty J and Kelly DJ: 3D bioprinting for cartilage and osteochondral tissue engineering. Adv Healthc Mater 6, 2017.

7. Bianco P and Robey PG: Stem cells in tissue engineering. Nature 414: 118-121, 2001.

8. Reddi AH: Role of morphogenetic proteins in skeletal tissue engineering and regeneration. Nat Biotechnol 16: 247-252, 1998.

9. El-Rashidy AA, Roether JA, Harhaus L, Kneser U and Boccaccini AR: Regenerating bone with bioactive glass scaffolds: A review of in vivo studies in bone defect models. Acta Biomater 62: 1-28, 2017.

10. Barcak EA and Beebe MJ: Bone morphogenetic protein: Is there still a role in orthopedic trauma in 2017? Orthop Clin North Am 48: 301-309, 2017.

11. Krishnakumar GS, Roffi A, Reale D, Kon E and Filardo G: Clinical application of bone morphogenetic proteins for bone healing: A systematic review. Int Orthop 41: 1073-1083, 2017.

12. Nguyen V, Meyers CA, Yan N, Agarwal S, Levi B and James AW: BMP-2-induced bone formation and neural inflammation. J Orthop 14: 252-256, 2017.

13. Vijayan V, Gupta S and Gupta S: Bone morphogenetic protein-5, a key molecule that mediates differentiation in MC3T3E1 osteoblast cell line. Biofactors 43: 558-566, 2017.

14. Yoo HS, Chung KH, Lee KJ, Kim DH and An JH: Melanin extract from Gallus gallus domesticus promotes proliferation and differentiation of osteoblastic MG-63 cells via bone morphogenetic protein-2 signaling. Nutr Res Pract 11: 190-197, 2017.

15. Yang D, Anderson PH, Wijenayaka AR, Barratt KR, Triliana R, Stapledon CJM, Zhou H, Findlay DM, Morris HA and Atkins GJ: Both ligand and VDR expression levels critically determine the effect of $1 \alpha, 25$-dihydroxyvitamin- $\mathrm{D}_{3}$ on osteoblast differentiation. J Steroid Biochem Mol Biol 177: 83-90, 2018.

16. Kubota K, Iseki S, Kuroda S, Oida S, Iimura T, Duarte WR, Ohya K, Ishikawa I and Kasugai S: Synergistic effect of fibroblast growth factor-4 in ectopic bone formation induced by bone morphogenetic protein-2. Bone 31: 465-471, 2002.

17. Narayanan KB and Han SS: Icosahedral plant viral nanoparticles-bioinspired synthesis of nanomaterials/nanostructures. Adv Colloid Interface Sci 248: 1-19, 2017.
18. Lai RF, Li ZJ,Zhou ZY, Feng ZQ and Zhao QT: Effect of rhBMP-2 sustained-release nanocapsules on the ectopic osteogenesis process in Sprague-Dawley rats. Asian Pac J Trop Med 6: 884-888, 2013.

19. Betz VM, Betz OB, Rosin T, Keller A, Thirion C, Salomon M, Manthey S, Augat P, Jansson V, Müller PE, et al: The effect of BMP-7 gene activated muscle tissue implants on the repair of large segmental bone defects. Injury 46: 2351-2358, 2015.

20. Cao H, Sun ZB, Zhang L, Qian W, Li CY, Guo XP and Zhang Y: Adenovirus-mediated bone morphogenetic protein-2 promotes osteogenic differentiation in human mesenchymal stem cells in vitro. Exp Ther Med 14: 377-382, 2017.

21. Hu M, Cui F, Liu F, Wang J, Wei X and Li Y: BMP signaling pathways affect differently migration and invasion of esophageal squamous cancer cells. Int J Oncol 50: 193-202, 2017.

22. Park S, Heo HA, Lee KB, Kim HG and Pyo SW: Improved bone regeneration with multiporous PLGA scaffold and BMP-2-transduced human adipose-derived stem cells by cell-permeable peptide. Implant Dent 26: 4-11, 2017.

23. Duan $P$ and Bonewald LF: The role of the wnt $/ \beta$-catenin signaling pathway in formation and maintenance of bone and teeth. Int J Biochem Cell Biol 77: 23-29, 2016.

24. Kobayashi $\mathrm{Y}$, Uehara S, Udagawa N and Takahashi N: Regulation of bone metabolism by Wnt signals. J Biochem 159: 387-392, 2016.

25. Xu J, Li Z, Hou Y and Fang W: Potential mechanisms underlying the Runx2 induced osteogenesis of bone marrow mesenchymal stem cells. Am J Transl Res 7: 2527-2535, 2015.

26. Liu JX, Yan ZP, Zhang YY, Wu J, Liu XH and Zeng Y: Hemodynamic shear stress regulates the transcriptional expression of heparan sulfate proteoglycans in human umbilical vein endothelial cell. Cell Mol Biol (Noisy-le-grand) 62: 28-34, 2016.

27. Deng Y, Guo T, Li J, Guo L, Gu P and Fan X: Repair of calvarial bone defect using jaridla-knockdown bone mesenchymal stem cells in rats. Tissue Eng Part A 24: 711-718, 2018.

28. Lin H, Tang Y, Lozito TP, Oyster N, Kang RB, Fritch MR, Wang B and Tuan RS: Projection stereolithographic fabrication of BMP-2 gene-activated matrix for bone tissue engineering. Sci Rep 7: $11327,2017$.

29. An G, Zhang WB, Ma DK, Lu B, Wei GJ, Guang Y, Ru CH and Wang YS: Influence of VEGF/BMP-2 on the proliferation and osteogenetic differentiation of rat bone mesenchymal stem cells on PLGA/gelatin composite scaffold. Eur Rev Med Pharmacol Sci 21: 2316-2328, 2017.

30. Wei F, Zhou Y, Wang J, Liu C and Xiao Y: The immunomodulatory role of BMP-2 on macrophages to accelerate osteogenesis. Tissue Eng Part A 24: 584-594, 2018.

31. Ishikawa H, Kitoh H, Sugiura F and Ishiguro N: The effect of recombinant human bone morphogenetic protein-2 on the osteogenic potential of rat mesenchymal stem cells after several passages. Acta Orthop 78: 285-292, 2007.

32. Simmons CA, Alsberg E, Hsiong S, Kim WJ and Mooney DJ: Dual growth factor delivery and controlled scaffold degradation enhance in vivo bone formation by transplanted bone marrow stromal cells. Bone 35: 562-569, 2004.

33. Roostaeian J, Carlsen B, Simhaee D, Jarrahy R, Huang W, Ishida K, Rudkin GH, Yamaguchi DT and Miller TA: Characterization of growth and osteogenic differentiation of rabbit bone marrow stromal cells. J Surg Res 133: 76-83, 2006.

34. Wang A, Ding X, Sheng S and Yao Z: Bone morphogenetic protein receptor in the osteogenic differentiation of rat bone marrow stromal cells. Yonsei Med J 51: 740-745, 2010.

35. Zhu L, Chuanchang D, Wei L, Yilin C and Jiasheng D: Enhanced healing of goat femur-defect using BMP7 gene-modified BMSCs and load-bearing tissue-engineered bone. J Orthop Res 28: 412-418, 2010.

36. Xu XL, Tang T, Dai K, Zhu Z, Guo XE, Yu C and Lou J: Immune response and effect of adenovirus-mediated human BMP-2 gene transfer on the repair of segmental tibial bone defects in goats. Acta Orthop 76: 637-646, 2005.

37. Li X, Peng J, Wu M, Ye H, Zheng C, Wu G, Xu H, Chen X and Liu X: BMP2 promotes chondrocyte proliferation via the Wnt/ $\beta$-catenin signaling pathway. Mol Med Rep 4: 621-626, 2011.

38. Qian C, Zhu C, Yu W, Jiang X, Zhang F and Sun J: Bone morphogenetic protein 2 promotes osteogenesis of bone marrow stromal cells in type 2 diabetic rats via the Wnt signaling pathway. Int J Biochem Cell Biol 80: 143-153, 2016.

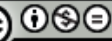

This work is licensed under a Creative Commons Attribution-NonCommercial-NoDerivatives 4.0 International (CC BY-NC-ND 4.0) License. 